\title{
Corticosteroid and antiviral therapy for Bell's palsy: A network meta-analysis
}

Pawin Numthavaj ${ }^{1}$, Ammarin Thakkinstian ${ }^{1 *}$, Charungthai Dejthevaporn², John Attia ${ }^{3}$

\begin{abstract}
Background: Previous meta-analyses of treatments for Bell's palsy are still inconclusive due to different comparators, insufficient data, and lack of power. We therefore conducted a network meta-analysis combining direct and indirect comparisons for assessing efficacy of steroids and antiviral treatment (AVT) at 3 and 6 months.

Methods: We searched Medline and EMBASE until September 2010 using PubMed and Elsviere search engines. A network meta-analysis was performed to assess disease recovery using a mixed effects hierarchical model. Goodness of fit of the model was assessed, and the pooled odds ratio (OR) and 95\% confidence interval (CI) were estimated.

Results: Six studies (total $n=1805$ )were eligible and contributed to the network meta-analysis. The pooled ORs for resolution at 3 months were 1.24 (95\% Cl: 0.79 - 1.94) for Acyclovir plus Prednisolone and 1.02 (95\% Cl: 0.73 - 1.42) for Valacyclovir plus Prednisolone, versus Prednisolone alone. Either Acyclovir or Valacyclovir singly had significantly lower efficacy than Prednisolone alone, i.e., ORs were 0.44 ( $95 \%$ Cl: 0.28 - 0.68) and 0.60 (95\% Cl: 0.42 - 0.87), respectively. Neither of the antiviral agents was significantly different compared with placebo, with a pooled OR of 1.25 (95\% Cl: 0.78 - 1.98) for Acyclovir and 0.91 (95\% Cl: 0.63 - 1.31) for Valacyclovir. Overall, Prednisolone-based treatment increased the chance of recovery 2 -fold (95\% Cl: 1.55 - 2.42) compared to non-Prednisolone-based treatment. To gain 1 extra recovery, 6 and 26 patients need to be treated with Acyclovir and prednisolone compared to placebo and prednisolone alone, respectively.

Conclusions: Our evidence suggests that the current practice of treating Bell's palsy with AVT plus corticosteroid may lead to slightly higher recovery rates compared to treating with prednisone alone but this does not quite reach statistical significance; prednisone remains the best evidence-based treatment.
\end{abstract}

\section{Background}

Bell's palsy is a condition characterized by an acute onset of facial nerve palsy with no known cause. The incidence is about $20 /$ year/100,000 population [1], and leads to a considerable disturbance in social activities among patients[2].

Although the actual cause of Bell's palsy is unknown, the widely accepted mechanism is inflammation of the facial nerve during its course through the bony labyrinthine part of the facial canal, which leads to compression and demyelination of the axons, and disruption of blood supply to the nerve itself[3]. Previous studies have suggested viral infection as the etiology of the disease

\footnotetext{
* Correspondence: raatk@mahidol.ac.th

${ }^{1}$ Section for Clinical Epidemiology and Biostatistics, Faculty of Medicine,

Ramathibodi Hospital, Mahidol University, Bangkok, Thailand

Full list of author information is available at the end of the article
}

based on serological evidence;[4,5] for example, positive serology for Herpes Simplex virus (HSV) has been reported in $20-79 \%$ of patients.

Treatment of Bell's palsy varies, and no clear consensus exists. Most physicians prescribe corticosteroids as a primary treatment due to its potential to reduce swelling and inflammation. The addition of antiviral treatment (AVT) such as Acyclovir or Valacyclovir is aimed at eradication of HSV infection. Acyclovir, a nucleoside analog, inhibits HSV replication through inhibition of viral DNA polymerase. It is absorbed slowly from the gastrointestinal tract, necessitating the use of a five-times daily regimen. Valacyclovir, a Valine derivative of Acyclovir, is claimed to lead to higher drug levels through conversion to Acyclovir by intestinal and hepatic esterase enzymes, leading to less intensive regimens. Its distribution,

\section{() Biomed Central}


cellular kinetics, mechanism, and excretion are otherwise identical to Acyclovir[6].

Efficacy of AVT in Bell's palsy is still not established, and the question exists whether adding AVT to another treatment such as corticosteroid can lead to better and faster recovery compared with corticosteroids alone or without treatment. The original Cochrane systematic review of this topic[7] included 3 studies; these were heterogeneous however and could not be pooled. Since that date, there have been at least 3 more large individual studies [8-13] and 3 more recent meta-analyses [14-16] published, although the comparator groups vary considerably and make traditional direct meta-analysis difficult. The meta-analsis by de Almeida et al. applied logistic regression analysis to assess interation effects between corticosteroids and AVT, however this does not account for heterogeneity and did not estimate the individual effect of AVT(Acyclovir or Valacyclovir). Furthermore, the review combined adult and paediatric studies (6 studies), in which dosages and effects of treatments may be different. The most recent update of the Cochrane systematic review included 6 studies [17], but did not look at the effects of AVTs alone. We therefore conducted a systematic review and network metaanalysis with the aim of comparing complete recovery rates at 3 and 6 months for corticosteroids, AVT (Acyclovir or Valacyclovir), or the combination of both for treatment of adult Bell's palsy. Performing a network meta-analysis by borrowing information from indirect comparisons integrates information about relative treatment efficacy[18-20]. This technique has been applied in systematic reviews of other clinical topics such as chronic insomnia[21], polymer-based drug-eluting stents [22], and highly-active AVT[23].

\section{Methods}

\section{Search strategy}

One author (NP) located studies in MEDLINE (from 1966 to August 2010) and EMBASE (from 1950 to September 2010) using PubMed and Ovid search engines. Search terms used were as follows: (Bell's palsy or idiopathic facial palsy) and (antiviral agents or acyclovir or valacyclovir), limited to randomized controlled trials. Search strategies for both databases are described in the additional file 1 .

\section{Selection of study and inclusion/exclusion criteria}

Abstracts and/or full papers of identified studies were reviewed by one author (NP) and checked by another author (TA). Studies were included if they were RCTs, and studied subjects aged 18 years or older with sufficient data. Non-English papers were excluded from the review. Where eligible papers had insufficient information, corresponding authors were contacted by e-mail for additional information. The reference lists of the retrieved papers were also reviewed to identify relevant publications. Where there were multiple publications from the same study group, the most complete and recent results were used.

\section{Data extraction \& Quality assessment (QA)}

Data extraction was independently performed in duplicate by PN and AT using a standardized data extraction form, which included study design, sample size, patient characteristics (i.e., age, gender), type of intervention and comparator, outcomes, and follow-up time. Any disagreement was resolved by discussion.

Quality of studies was also independently assessed by PN and AT based on a modified Jadad score which takes into account randomization technique, allocation concealment, blinding, intention to treat, and patient attrition[24]. Each item was graded 2, 1, or 0 for appropriately, partially, and inappropriately described methods. Any disagreement between the two reviewers was discussed and resolved by consensus.

\section{Outcome}

Complete recovery was defined as a score $\leq 2$ on the House-Brackman Facial Recovery scale[12,13,25], $\geq 8$ on the Facial Palsy Recovery Index[8], > 36 points on theYanagihara score[10], or 100 on the Sunnybrook scale[9].

\section{Statistical analysis}

For direct meta-analysis, the odds ratio (OR) and variance of each study were estimated and pooled. Heterogeneity of ORs was assessed using Cochran's Q test and $\mathrm{I}^{2}$. If heterogeneity was present, ORs were pooled using the random effects model, i.e. Der-Simonian and Laird method. Meta-regression was applied to assess whether age, gender, and QA were sources of heterogeneity, if these data were available. Contour enhanced funnel plots were used to detect publication bias due to small study effects [26-29]. Trim and fill meta-analysis was applied to impute the number of missing studies [30].

For network meta-analysis, treatment groups were considered in a mixed effects hierarchical model with logit link function using the xtmelogit command in STATA[31]. The treatments were included in the model as fixed effects whereas the study was included as a random effect. Likelihood estimates were used for estimation of parameters in the model. Goodness of fit of the model was assessed using the Hosmer-Lemeshow Chisquare test. The pooled ORs and 95\% confidence intervals $(\mathrm{CI})$ were estimated by exponential coefficients of treatments. Discrepancy of treatment effects between direct and indirect meta-results was then assessed using the standardized normal method (Z), i.e. by dividing the 
difference by its standard error[20,32]. Number needed to treat/harm (NNT/NNH) was estimated using probability of complete recovery and ORs derived from the mixed effects hierarchical model, where the ORs were converted to risk ratios following the method of Zhang et al[33]. All analyses were performed using STATA version 11.0. P values $<0.05$ were considered as statistically significant except for the heterogeneity test where $<0.10$ was used.

\section{Results}

A flow diagram of study selection is shown in Figure 1. Fourteen and twenty-five studies were identified from MEDLINE and EMBASE databases, respectively. Among these 39 studies, 1 studies were duplicates, 13 studies were ineligible, leaving 12 studies to review. Six studies were excluded; two were in Spanish, one was in German, and 3 were subsets or duplicated reports, leaving six studies[8-10,12,13,25] with a total of 1805 patients for analysis. Characteristics of the 6 included studies are described in table 1. Five studies[8-10,12,13] compared recovery rates of AVT plus corticosteroid with corticosteroid alone or placebo; the remaining study directly compared the recovery rate of AVT against corticosteroid[25]. Two studies were based on factorial design $[9,12]$ and the others were parallel randomized control trials. The AVTs used were Acyclovir for 4 studies[8,12,13,25] and Valacyclovir for the other 2 studies[9,10]. Prednisolone was the major corticosteroid used. Mean age of participants in these studies ranged from 40 to 50 years, and percentage of male participants ranged from $45 \%$ to $59 \%$. Median quality assessment score was 8 (range $=2-12$ ).

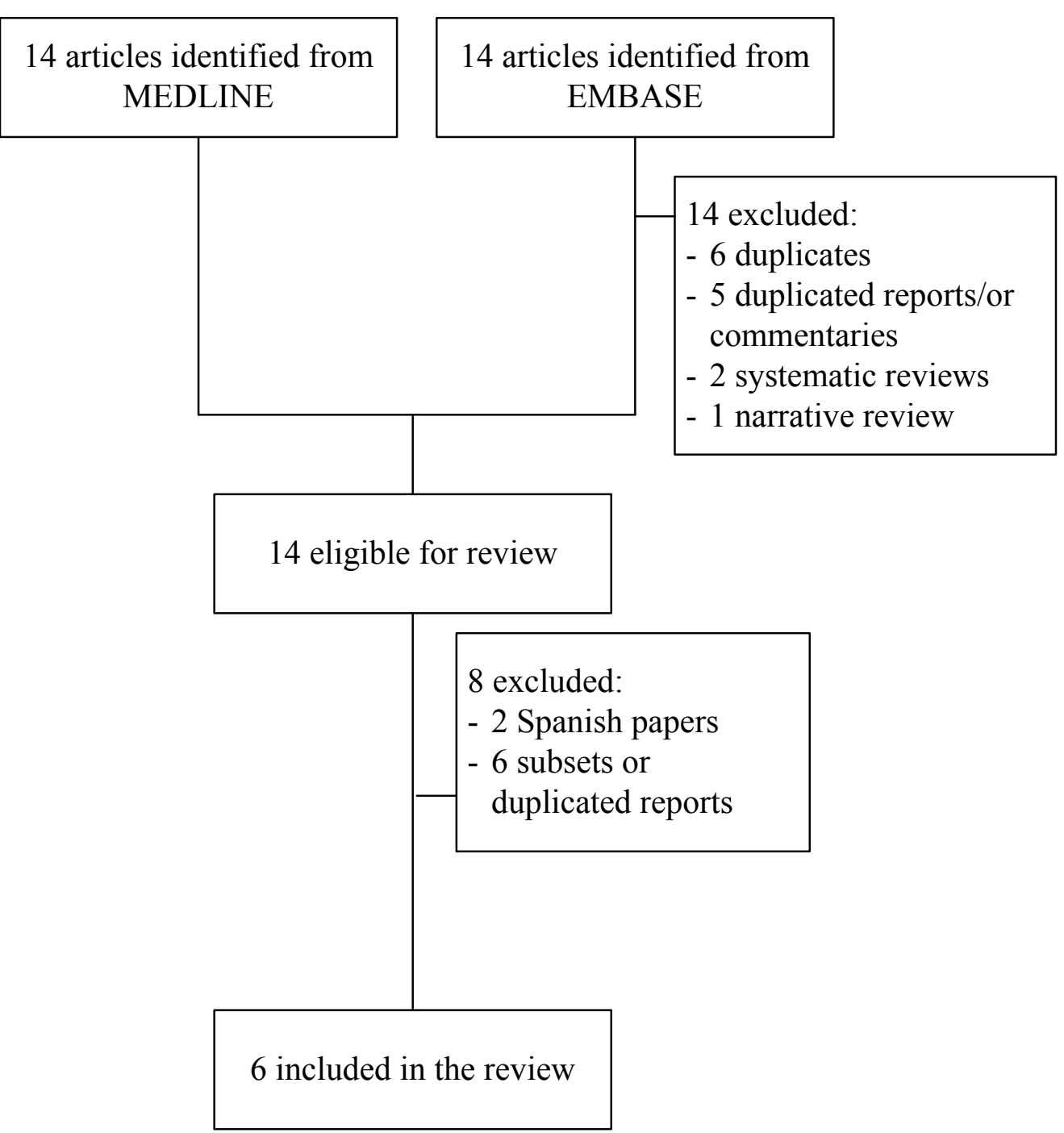

Figure 1 Diagram of selection of studies. 
Table 1 Baseline characteristics of included studies

\begin{tabular}{|c|c|c|c|c|c|c|c|c|c|}
\hline \multirow{2}{*}{$\begin{array}{c}\text { Author } \\
\text { (Year) }\end{array}$} & \multirow[t]{2}{*}{$\mathbf{N}$} & \multirow{2}{*}{$\begin{array}{l}\text { Mean } \\
\text { age }\end{array}$} & \multirow{2}{*}{$\begin{array}{c}\% \text { Male } \\
\text { Participants }\end{array}$} & \multirow{2}{*}{$\begin{array}{l}\text { Mean } \\
\text { disease } \\
\text { severity } \\
\text { score }\end{array}$} & \multicolumn{2}{|l|}{ Type of treatment } & \multirow[t]{2}{*}{ Outcomes } & \multirow{2}{*}{$\begin{array}{l}\text { FU time } \\
\text { (month) }\end{array}$} & \multirow{2}{*}{$\begin{array}{l}\text { QA } \\
\text { score }\end{array}$} \\
\hline & & & & & Intervention (dosage) & Control & & & \\
\hline $\begin{array}{l}\text { Adour } \\
\text { et al. } \\
(1996)[8]\end{array}$ & 99 & 43 & 50 & 3 (FPRP) & $\begin{array}{l}\text { Acyclovir } 2,000 \mathrm{mg} / \text { day } \times 10 \text { days } \\
\text { Prednisolone } 30 \mathrm{mg} / \mathrm{kg} / \text { day } \times 5 \text { days, } \\
10 \mathrm{mg} / \text { day } \times \text { next } 5 \text { days }\end{array}$ & $\begin{array}{l}\text { Prednisolone } \\
\text { with the same } \\
\text { dosage }\end{array}$ & $\mathrm{FPRI} \geq 8$ & 4 & 7 \\
\hline $\begin{array}{l}\text { De Diego } \\
\text { et al. } \\
(1998)[25]\end{array}$ & 101 & - & - & - & Acyclovir $2,400 \mathrm{mg} /$ day $\times 10$ days & $\begin{array}{l}\text { Prednisolone } 1 \\
\mathrm{mg} / \mathrm{kg} / \text { day } \times \\
10 \text { days, taper } \\
\text { over next } 6 \\
\text { days }\end{array}$ & $\begin{array}{l}\text { HB grade } \leq \| 1, \\
\text { FPRI score } \geq 8\end{array}$ & 3 & 3 \\
\hline $\begin{array}{l}\text { Hato et al. } \\
\text { (2007)[10] }\end{array}$ & 221 & 50 & 53 & $\begin{array}{c}15 \\
\text { (Yanagihara) }\end{array}$ & $\begin{array}{l}\text { Valacyclovir } 1,000 \mathrm{mg} / \text { day } \times 5 \text { days } \\
\text { Prednisolone } 60 \mathrm{mg} / \text { day for } 5 \text { days, } \\
\text { taper with Mecobalamin } 1.5 \mathrm{mg} / \text { day } \times \\
6 \text { months }\end{array}$ & Placebo & $\begin{array}{l}\text { Yanagihara score } \\
>36 \text { points, no } \\
\text { facial contracture } \\
\text { or synkinesis }\end{array}$ & 6 & 9 \\
\hline $\begin{array}{l}\text { Sullivan et } \\
\text { al. (2007) } \\
\text { [12] }\end{array}$ & 551 & 44 & 51 & $3.6(\mathrm{HB})$ & $\begin{array}{l}\text { Acyclovir } 2000 \mathrm{mg} / \text { day } \times 10 \text { days } \\
\text { Prednisolone } 50 \mathrm{mg} / \text { day } \times 10 \text { days }\end{array}$ & Placebo & HB grade I & 3,9 & 12 \\
\hline $\begin{array}{l}\text { Yeo et al. } \\
\text { (2008)[13] }\end{array}$ & 91 & 41 & 45 & $3.7(\mathrm{HB})$ & $\begin{array}{l}\text { Acyclovir } 2,400 \mathrm{mg} / \text { day } \times 5 \text { days } \\
\text { Prednisolone } 1 \mathrm{mg} / \mathrm{kg} / \text { day } \times 4 \text { days } \\
\text { with maximum of } 80 \mathrm{mg} / \text { day, } 60 \mathrm{mg} / \\
\text { day } \times 5-6 \text { day, } 40 \mathrm{mg} / \text { day } \times 7-8 \text { day, } \\
20 \mathrm{mg} / \text { day } \times 9-10 \text { day }\end{array}$ & Placebo & $\mathrm{HB}$ grade $\leq \|$ & 2,6 & 2 \\
\hline $\begin{array}{l}\text { Engstrom } \\
\text { et al. } \\
\text { (2008) [9] }\end{array}$ & 829 & 40 & 59 & 4 by $\mathrm{HB}$ & $\begin{array}{l}\text { Valacyclovir } 3,000 \mathrm{mg} / \text { day } \times 7 \text { days } \\
\text { Prednisolone } 60 \mathrm{mg} / \text { day } \times 5 \text { days, } 10 \\
\mathrm{mg} / \text { day until } 10 \text { days }\end{array}$ & Placebo & $\begin{array}{l}\text { Sunnybrook 100/ } \\
100, H B \leq \|\end{array}$ & $\begin{array}{l}1,2,3 \\
6,12\end{array}$ & 12 \\
\hline
\end{tabular}

\section{Direct comparisons}

Among 6 studies, 3 studies $[8,12,13]$ compared recovery rates within 3 months between Acyclovir plus Prednisolone versus Prednisolone alone (table 2). Pooled treatment effects were heterogeneous (Chi-sqaure $=6 \cdot 30($ d.f. $=2$ ) $\left.\mathrm{p}=0.043 ; \mathrm{I}^{2}=68.3 \%\right)$. Using the random effects model gave a pooled OR of $1.39(95 \% \mathrm{CI}:=0.52-3.75)$, i.e. patients who received Acyclovir plus Prednisolone were about 40\% more likely to recover within 3 month than patients who received Prednisolone alone, although this did not reach statistical significance. Only 2 studies $[9,10]$ compared recovery rates between Valacyclovir plus Prednisolone and Prednisolone. They were homogeneous and the pooled OR with fixed effect model was $1 \cdot 17$ (95\% CI: 0.75 - 1.81).

Combining 5 studies[8-10,12,13] to assess the effect of AVT (Acyclovir/Valacyclovir) plus Prednisolone versus Prednisolone found moderate heterogeneity (Chi-sqaure $=$ 7.78 (d.f. = 4) $\left.\mathrm{p}=0.100 ; \mathrm{I}^{2}=48.6 \%\right)$. The pooled OR with

Table 2 Describe numbers of recovery according to treatment groups for each included study

\begin{tabular}{|c|c|c|c|c|c|}
\hline Author & Treatment groups & Recovery at 3 months & Total $\mathbf{N}$ & Recovery after 3 months & Total $\mathbf{N}$ \\
\hline \multirow[t]{2}{*}{ Adour et al. [8] } & Acy+Pred & 34 & 38 & 49 & 53 \\
\hline & Pred & 20 & 29 & 35 & 46 \\
\hline \multirow[t]{2}{*}{ De Diego[25] } & Acy & 42 & 54 & - & - \\
\hline & Pred & 44 & 47 & - & - \\
\hline \multirow[t]{4}{*}{ Engstorm et al. [9] } & Val+Pred & 134 & 206 & 149 & 206 \\
\hline & Val & 113 & 207 & 120 & 207 \\
\hline & Pred & 137 & 210 & 150 & 210 \\
\hline & Plac & 111 & 206 & 127 & 206 \\
\hline \multirow[t]{2}{*}{ Hato et al. [10] } & Val+Pred & 94 & 114 & 110 & 114 \\
\hline & Pred & 80 & 107 & 96 & 107 \\
\hline \multirow[t]{4}{*}{ Sullivan et al. [12] } & Acy+Pred & 99 & 124 & 115 & 124 \\
\hline & Acy & 76 & 123 & 96 & 123 \\
\hline & Pred & 109 & 127 & 122 & 127 \\
\hline & Plac & 79 & 122 & 104 & 122 \\
\hline \multirow[t]{2}{*}{ Yeo et al. [13] } & Acy + Pred & 36 & 44 & 41 & 44 \\
\hline & Pred & 35 & 47 & 40 & 47 \\
\hline
\end{tabular}


a random effect model was 1.21 (95\% CI: $0.77-1.89$ ), i.e. AVT plus Prednisolone had $21 \%$ higher chance of complete recovery than Prednisolone alone but this was non-significant. Meta-regression suggested that quality assessment score and disease severity at baseline might be a source of heterogeneity, reducing $\mathrm{I}^{2}$ from $48.6 \%$ to $32.5 \%$ and $15.5 \%$ respectively although both variables were non-significantly associated with treatment effects. Pooling studies with quality assessment scores $>8$ (median) suggested no benefit of AVT plus Prednisolone compared with Prednisolone alone (pooled OR $=1.01,95 \% \mathrm{CI}: 0.74-1.37$ ). Two studies $[8,10]$ had more severe patients at baseline (i.e., mean scores were 3 by facial palsy recovery index and 15 by Yanagihara score) compared with the other 3 studies $[9,12,13]$ (i.e., mean scores were 3.6 to 4 by HB), see table 1. Pooling within the severe group only suggested the possibility of a treatment effect but this was nonsignificant $(\mathrm{OR}=2.04,95 \% \mathrm{CI}: 0.93-4.46)$ while treatment effect was close to the null in the less severe group $(\mathrm{OR}=0.94,95 \% \mathrm{CI}: 0.66-1.33)$. Contour enhanced funnel plots suggested asymmetry, i.e., four studies lay in the non-sigificant area (white, $\mathrm{p}>5 \%$ ) but the study with the largest treatment effect and SE lay in the positive-moderate significant area $(1 \% \leq \mathrm{p} \leq$ $5 \%$, see Figure 2), suggesting that the asymmetry might be due to missing, non-significant studies. "metatrim" analysis indicated that only one negative study with borderline significance was missing; adjusting for this presumed missing studies resulted in an ORof 1.08 (95\% CI: 0.66 - 1.76).

Three studies $[8,12,13]$ reported the recovery rate between direct comparisons of Acyclovir plus Prednisolone versus Prednisolone after receiving treatments at 4 to 9 months (table 2). Treatment effects were statistically heterogeneous (Chi-square $=6.07($ d.f. $=2), p=0.048$; $\mathrm{I} 2=67.0 \%)$, and the random effects pooled OR was 1.63 (95\% CI: 0.47 - 5.75). Pooling effects of Valacyclovir plus Prednisolone versus Prednisolone was performed based on only 2 heterogeneous studies $[9,10]$. The random effects pooled OR was 1.58 (95\% CI: 0.55 - 4.48). There was only 1 study each that compared Acyclovir [12] or Valacyclovir[9] alone versus Prednisolone and this was insufficient for pooling.

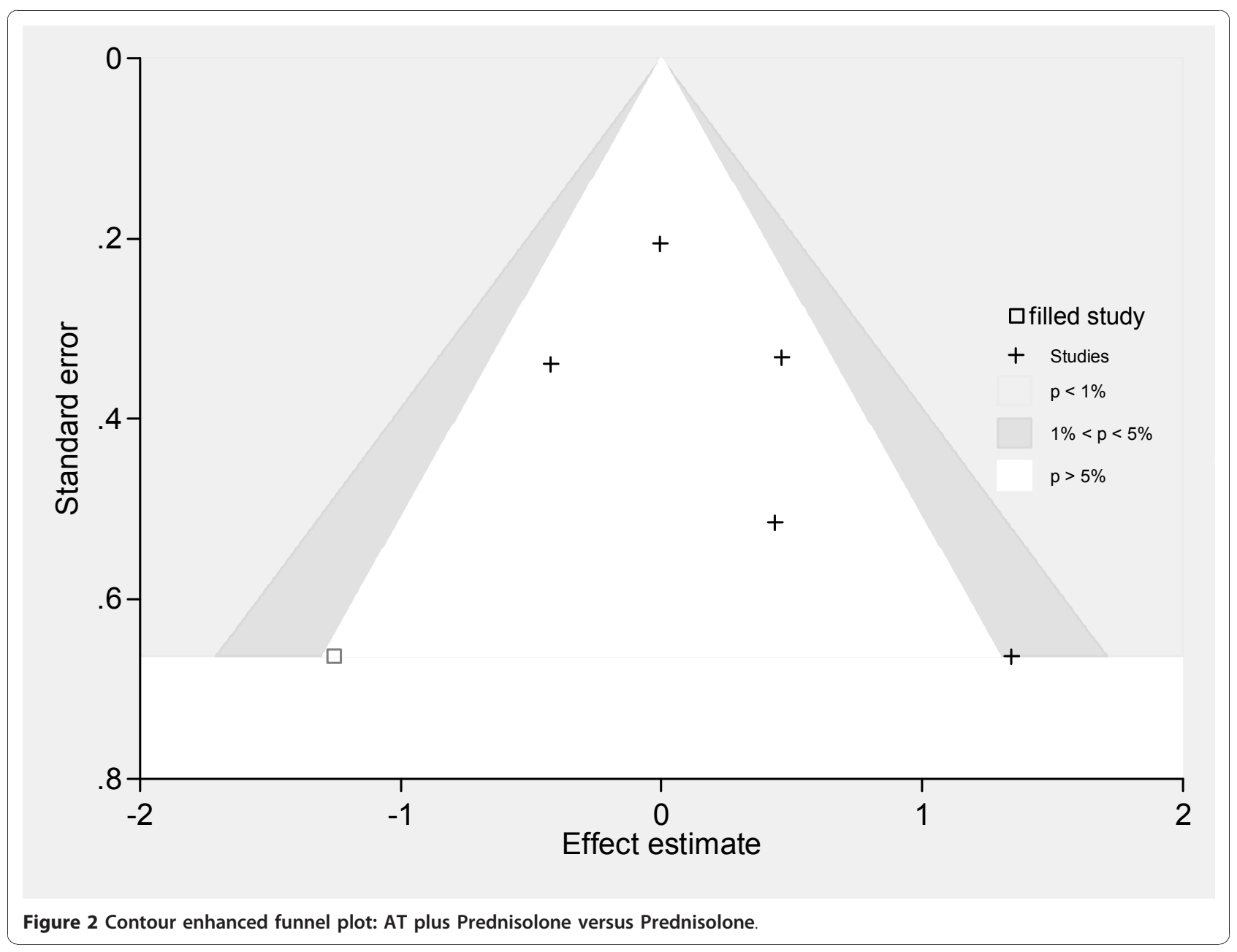




\section{Network meta-analysis}

All six studies[8-10,12,13,25] were able to contribute to a network meta-analysis, for a total of 1,805 patients, as described in table 2. Overall, 177 (9.8\%), 207 (11.5\%), $567(31.4 \%)$, and $328(18.2 \%)$ received only Acyclovir, Valacyclovir, Prednisolone, or placebo whereas 206 (11.4\%) and 320 (17.7\%) received Acyclovir plus Prednisolone and Valacyclovir plus Prednisolone, respectively. One-thousand two-hundred and forty-three patients had complete recovery (68.9\%) within three months.

All treatment comparisons and results of the network meta-analysis for 3 month outcomes are displayed in Figure 3a. Each line in the figure represents a randomized comparison, in which the head and the tail of that line refer to intervention and reference groups respectively. Figures on the lines refer to estimated indirect ORs for that comparison; ORs less than one indicate that the intervention group had lower recovery than the reference group, whereas ORs higher than one mean that the intervention group had higher recovery than the reference group. The mixed-effects model with a random intercept and a constant slope was applied to assess treatment effects. The estimated variance between studies was 0.17 (95\% CI: 0.04 - 0.76). HosmerLemeshow test found that the model was a good fit (Chi-square $=12 \cdot 99, \mathrm{p}=0 \cdot 072$ ).

Treatment effects for all comparisons are shown in Figure $3 \mathrm{a}$ and table 3. Adding Acyclovir or Valacyclovir to Prednisolone did not significantly increase recovery rate when compared with Prednisolone alone, although the point estimates suggest a potential benefit of the combination, i.e., ORs were 1.24 (95\% CI: 0.79 - 1.94) and 1.02 (95\% CI: 0.73 - 1.42) for Acyclovir and Valacyclovir, respectively. For monotherapy, either Acyclovir $(\mathrm{OR}=$ $0.44,95 \%$ CI: $0.28-0.68$ ) or Valacyclovir (OR =0.60, 95\% CI: $0.42-0.87$ ) led to significantly lower recovery than Prednisolone alone and this was not significantly different compared with placebo $(\mathrm{OR}=1.25,95 \% \mathrm{CI}$ : 0.78 1.98 for Placebo versus Acyclovir; OR = 0.91, 95\% CI: 0.63 - 1.31 for Placebo versus Valacyclovir). These data indicate that Prednisolone led to higher recovery rates than not receiving Predisolone. We therefore combined all Prednisolone groups (regardless of additional AVT) compared with non-Prednisolone (i.e., Acyclovir, Valacyclovir, and Placebo). The estimated OR was 1.94 (95\% CI: 1.55 - 2.42), i.e., Prednisolone-based treatment increase the chance of recovery by 3 months by 2 fold compared to non-Prednisolone-based treatment.

These effects were largely consistent when recovery was judged at later time points (Figure $3 \mathrm{~b}$ and table 3 ). Acyclovir (OR $=1.74,95 \%$ CI: $0.93-3.24$ ) or Valacyclovir $(\mathrm{OR}=1.15$, 95\% CI: 0.78 - 1.69) added to Prednisolone tended to improve recovery rates compared to receiving Prednisolone alone but the effects were non-significant. Mono-therapy with either Acyclovir $(\mathrm{OR}=0.33$, 95\% CI: $0.18-0.68)$ or Valacyclovir $(\mathrm{OR}=$ $0.55,95 \%$ CI: $0.37-0.81$ ), or placebo $(\mathrm{OR}=0.62,95 \%$ CI: $0.43-0.88)$ led to significantly lower recovery than Prednisolone mono-therapy. Compared with Acyclovir, Acyclovir or Valacyclovir plus Prednisolone was more beneficial than Acyclovir alone, with ORs of 5.21 (95\% CI: 2.48 - 10.94) and 3.45 (95\% CI: 1.78 - 6.68) respectively; trends were similar for Valacyclovir. Overall, the effect of prednisolone-based regimens compared to those without prednisolone was similar to that at 3 months, with OR of 2.04 (95\% CI 1.57 - 2.64).

\section{Comparison of direct and network meta-analysis}

Results of direct and network analyses are compared in the last column of table 3. Direction of treatment effects between both methods were similar for all comparisons, although the direct approach provided higher treatment effects in both positive and negative directions. The degree of discrepancy between the 2 methods was very small except for Acyclovir versus Prednisolone, where $\mathrm{Z}$ was large and significant at 3 and 6 months $(1 \cdot 77, \mathrm{p}=$ 0.077 ; and $-2.93, \mathrm{p}=0.002$ respectively). Precision of treatment effects was generally higher in the network meta-analysis than the direct one.

Finally, estimates of NNT and NNH for recovery at 3 and 6 months are given in table 4 . We found that 6 patients need to be treated with Acyclovir and prednisolone compared to placebo in order to gain 1 extra recovery and this had a tight confidence interval. By contrast, the benefit of combination AT and prednisolone compared to prednisolone alone was less certain, with 26 patients needing to be treated with Acyclovir plus predinisolone in order to gain 1 extra patient with recovery at 3 months, and this had wide confidence intervals.

\section{Discussion}

Our network meta-analysis indicates that treatment with AVT alone or placebo is significantly inferior to Prednisolone alone; the effect of AVT alone and placebo are similar to each other. Current practice of adding AVT (either Acyclovir or Valacyclovir) in the regimen with Prednisolone may increase disease recovery rates compared with Prednisolone alone, but at this point this difference is not statistically significant. Prednisolone remains the strongest evidence-based treatment, whether compared to placebo or AVT monotherapy.

The possible explanations for the lack of any incremental effect of AVT when added to corticosteroids might include:

- corticosteroids reduces the inflammatory process in Bell's palsy and this facilitates remyelination of facial nerve. 

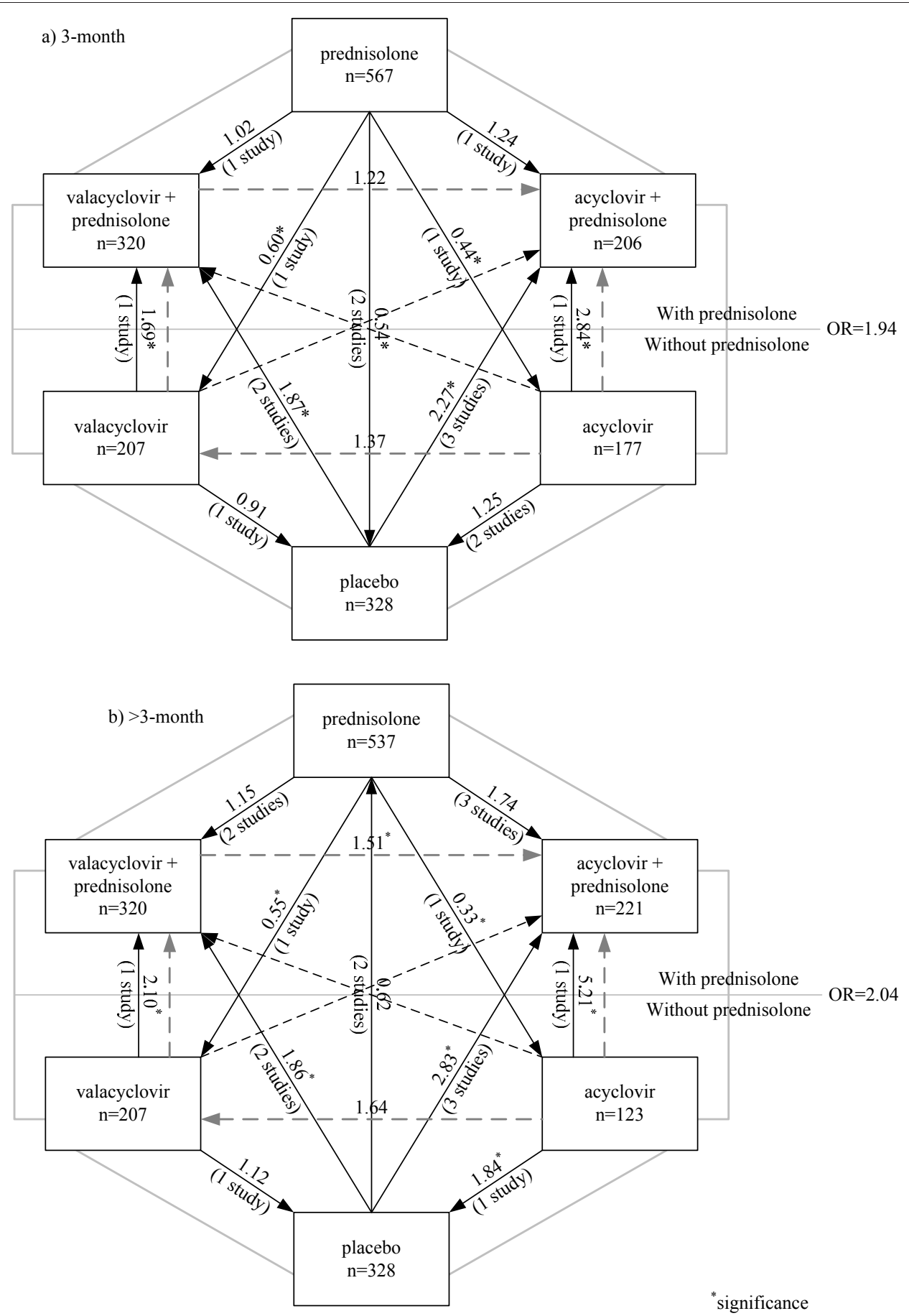

Figure 3 Comparisons of recovery rates between treatment groups: A network meta-analysis. a) at 3 months. b) at $>3$ months.

- Bell's palsy is a post-infectious immune mediated facial neuropathy rather than direct viral infection - There may be a small incremental increase in efficacy but there is not sufficient power, even with all the trials to date, to demonstrate this. Large RCTs are needed to specifically compare corticosteroid and corticosteroid plus AVT.
This meta-analysis demonstrates well the advantage of the network approach. Assessing the efficacy of treatments for Bell's palsy based on results of individual RCTs and direct meta-analysis is difficult due to the fact that there are various treatment regimens, and too few studies performing the same treatment comparisons for pooling. For instance, 6 treatment regimens are possible 
Table 3 Comparisons of treatment effects on disease recovery at 3 months between direct and network meta-analyses

\begin{tabular}{|c|c|c|c|c|c|c|c|c|c|c|c|c|}
\hline \multirow[t]{2}{*}{ Time at assessment } & \multirow[t]{2}{*}{ Intervention Group } & \multirow[t]{2}{*}{ Reference Group } & \multicolumn{4}{|c|}{ Direct meta-analysis } & \multicolumn{4}{|c|}{ Network meta-analysis } & \multicolumn{2}{|c|}{ Discrepancy } \\
\hline & & & $\mathrm{n}$ & OR & $95 \% \mathrm{Cl}$ & SE & $\mathrm{n}$ & OR & $95 \% \mathrm{Cl}$ & SE & Z & $P$ value \\
\hline \multirow[t]{15}{*}{3 month } & Acy + Pred & Pred & 409 & 1.39 & $0.52-3 \cdot 75$ & 0.32 & 773 & $1 \cdot 24$ & $0.79-1.94$ & 0.28 & 0.27 & 0.788 \\
\hline & Val + Pred & Pred & 637 & $1 \cdot 17$ & $0.75-1 \cdot 81$ & 0.22 & 887 & 1.02 & $0.73-1.42$ & 0.17 & 0.49 & 0.621 \\
\hline & Acy & Pred & 351 & 0.26 & $0.15-0.46$ & 0.28 & 744 & 0.44 & $0.28-0.68$ & $0 \cdot 10$ & $-1 \cdot 77$ & 0.077 \\
\hline & Val & Pred & 417 & 0.64 & $0.43-0.95$ & 0.21 & 774 & 0.60 & $0 \cdot 42-0 \cdot 87$ & 0.11 & 0.27 & 0.785 \\
\hline & Plac & Pred & 665 & 0.50 & $0 \cdot 36-0 \cdot 70$ & 0.17 & 895 & 0.54 & $0 \cdot 40-0 \cdot 74$ & 0.09 & -0.40 & 0.689 \\
\hline & Acy+Pred & Acy & 247 & $2 \cdot 45$ & $1 \cdot 33-4.53$ & 0.29 & 383 & $2 \cdot 84$ & $1.68-4.78$ & 0.75 & 0.83 & 0.20 \\
\hline & Val+Pred & Acy & - & - & - & - & 497 & $2 \cdot 32$ & $1.37-3.93$ & 0.62 & - & - \\
\hline & Val & Acy & - & - & - & - & 384 & 1.37 & $0.79-2.37$ & 0.38 & - & - \\
\hline & Plac & Acy & 245 & $1 \cdot 14$ & $0.65-1.98$ & 0.27 & 505 & 1.25 & $0.78-1.98$ & 0.29 & -0.23 & 0.41 \\
\hline & Acy+Pred & Val & - & - & - & - & 413 & 2.06 & $1.20-3.56$ & 0.57 & & \\
\hline & Val+Pred & Val & 413 & 1.55 & $1.02-2.35$ & 0.20 & 527 & 1.69 & $1 \cdot 16-2.48$ & 0.33 & -0.22 & 0.411 \\
\hline & Plac & Val & 413 & 0.97 & $0.65-1.45$ & 0.20 & 535 & 0.91 & $0.63-1.31$ & 0.17 & 0.24 & 0.404 \\
\hline & Acy+Pred & Plac & 246 & $2 \cdot 16$ & $1 \cdot 17-4.00$ & 0.29 & 534 & $2 \cdot 27$ & $1.31-2.66$ & 0.55 & -0.08 & 0.468 \\
\hline & Val+Pred & Plac & 412 & 1.59 & $1.05-2.42$ & 0.20 & 648 & 1.87 & $1.31-2.66$ & 0.34 & -0.41 & 0.340 \\
\hline & Acy+Pred & Val+Pred & - & - & - & - & 526 & 1.22 & $0.72-2.06$ & 0.32 & - & - \\
\hline \multirow[t]{15}{*}{6 month } & Acy + Pred & Pred & 441 & 1.63 & $0.47-5.75$ & 0.83 & 758 & 1.74 & $0.93-3 \cdot 24$ & 0.56 & -0.07 & 0.474 \\
\hline & Val + Pred & Pred & 637 & 1.58 & $0.55-4.48$ & 0.40 & 857 & $1 \cdot 15$ & $0.78-1.69$ & 0.23 & 0.67 & 0.246 \\
\hline & Acy & Pred & 250 & 0.15 & $0.04-0.41$ & 0.25 & 660 & 0.33 & $0 \cdot 18-0 \cdot 61$ & $0 \cdot 10$ & $-2 \cdot 93$ & 0.002 \\
\hline & Val & Pred & 417 & 0.55 & $0.36-0.85$ & 0.21 & 744 & 0.55 & $0.37-0.81$ & 0.11 & 0.00 & 0.500 \\
\hline & Plac & Pred & 665 & 0.44 & $0.17-1.14$ & 0.34 & 865 & 0.62 & $0.43-0 \cdot 88$ & 0.11 & -0.96 & 0.169 \\
\hline & Acy+Pred & Acy & 247 & 3.6 & $1.54-9.07$ & 0.41 & 344 & $5 \cdot 21$ & $2.48-10.94$ & 1.97 & -0.18 & 0.427 \\
\hline & Val+Pred & Acy & - & - & - & - & 443 & 3.45 & $1.78-6.68$ & $1 \cdot 16$ & - & - \\
\hline & Val & Acy & - & - & - & - & 330 & 1.64 & $0.85-3.18$ & 0.55 & - & - \\
\hline & Plac & Acy & 245 & 1.63 & $0.80-3.34$ & 0.34 & 451 & 1.84 & $1.02-3.33$ & 0.56 & -0.18 & 0.427 \\
\hline & Acy+Pred & Val & - & - & - & - & 428 & $3 \cdot 17$ & $1.57-6.40$ & $1 \cdot 14$ & & \\
\hline & Val+Pred & Val & 413 & 1.89 & $1.23-2.92$ & 0.21 & 527 & $2 \cdot 10$ & $1.40-3.15$ & 0.44 & -0.22 & 0.414 \\
\hline & Plac & Val & 413 & $1 \cdot 16$ & $0.77-1.76$ & 0.20 & 535 & $1 \cdot 12$ & $0.76-1.65$ & 0.22 & 0.12 & 0.453 \\
\hline & Acy+Pred & Plac & 246 & $2 \cdot 21$ & $0.89-5.82$ & 0.43 & 549 & $2 \cdot 83$ & $1.46-5.47$ & 0.95 & -0.24 & 0.406 \\
\hline & Val+Pred & Plac & 412 & 1.63 & $1.05-2.51$ & 0.21 & 648 & 1.86 & $1.26-2.77$ & 0.38 & -0.30 & 0.381 \\
\hline & Acy+Pred & Val+Pred & - & - & - & - & 541 & 1.51 & $0.75-3.05$ & 0.54 & - & - \\
\hline
\end{tabular}

Table 4 Estimated numbers needed to treat and numbers needed to harm of treatments

\begin{tabular}{|c|c|c|c|c|c|c|c|}
\hline \multirow{3}{*}{$\begin{array}{l}\text { Intervention Group } \\
\text { Acy + Pred }\end{array}$} & \multirow{3}{*}{$\begin{array}{l}\text { Reference Group } \\
\text { Pred }\end{array}$} & \multicolumn{3}{|c|}{ NNT/NNH (3 months) } & \multicolumn{3}{|c|}{ NNT/NNH (6 months) } \\
\hline & & \multirow{2}{*}{$\begin{array}{c}\text { Point Estimate } \\
\text { NNT } 26\end{array}$} & \multicolumn{2}{|c|}{$95 \% \mathrm{Cl}$} & \multirow{2}{*}{$\begin{array}{c}\text { Point Estimate } \\
\text { NNT } 15\end{array}$} & \multicolumn{2}{|c|}{$95 \% \mathrm{Cl}$} \\
\hline & & & NNH 21 & NNT 10 & & NNH 93 & NNT 9 \\
\hline Val + Pred & Pred & NNT 271 & NNH 16 & NNT 17 & NNT 52 & NNH 26 & NNT 16 \\
\hline Acy & Pred & $\mathrm{NNH} 6$ & NNH 3 & NNH 13 & $\mathrm{NNH} 5$ & $\mathrm{NNH} 3$ & $\mathrm{NNH} 12$ \\
\hline Val & Pred & $\mathrm{NNH} 9$ & $\mathrm{NNH} 5$ & NNH 37 & NNH 10 & NNH 5 & $\mathrm{NNH} 31$ \\
\hline Plac & Pred & $\mathrm{NNH} 8$ & NNH 5 & NNH 17 & NNH 13 & NNH 6 & NNH 52 \\
\hline Acy+Pred & Acy & NNT 8 & NNT 10 & NNT 4 & NNT 6 & NNT 8 & NNT 5 \\
\hline Val+Pred & Acy & NNT 3 & NNT 15 & NNT 5 & NNT 7 & NNT 12 & NNT 6 \\
\hline Val & Acy & NNT 15 & NNH 18 & NNT 6 & NNT 14 & NNH 34 & NNT 7 \\
\hline Plac & Acy & NNT 21 & NNH 17 & NNT 8 & NNT 11 & NNT 296 & NNT 7 \\
\hline Acy+Pred & Val & NNT 6 & NNT 22 & NNT 4 & NNT 4 & NNT 10 & NNT 3 \\
\hline Val+Pred & Val & NNT 8 & NNT 27 & NNT 5 & NNT 6 & NNT 13 & NNT 4 \\
\hline Plac & Val & NNH 43 & NNH 9 & NNT 15 & NNT 37 & NNH 15 & NNT 9 \\
\hline Acy+Pred & Plac & NNT 6 & NNT 16 & NNT 5 & NNT 6 & NNT 14 & NNT 4 \\
\hline Val+Pred & Plac & NNT 7 & NNT 16 & NNT 5 & NNT 9 & NNT 22 & NNT 6 \\
\hline Acy+Pred & Val+Pred & NNT 26 & NNH 14 & NNT 8 & NNT 18 & NNH 21 & NNT 8 \\
\hline
\end{tabular}


in clinical practice (i.e., Acyclovir, Valacyclovir, Prednisolone, Placebo, combination of Acyclovir + Prednisolone, and Valacyclovir + Prednisolone) resulting in 15 possible treatment-pair comparisons. Previous reviews have had problems with this multiplicity of comparisons:

- a previous systematic review of AVT versus corticosteroid[7] included only 3 studies with 246 patients, and these could not be pooled since each study had a different combination of treatments;

- one systematic review[34] included 3 studies with 117 patients and demonstrated no benefit of using corticosteroid compared with placebo/vitamin with relative risk of 0.86 (95\% CI: 0.47 - 1.59).

- Another review[15] included 5 studies with 709 samples and reported no benefit of AVT (OR = 1.03; 95\% CI: $0.74-1.42)$ when compared with Prednisolone.

The small numbers in these previous meta-analyses clearly led to lack of power. Two more complete reviews $[14,17]$ were recently published. One accessed unpublished and non-English papers and thus included more studies than other previous meta-analyses. Point estimates of treatment effects for our results were similar to theirs, although confidence intervals varied. For instance, the effect of corticosteroid versus placebo at longer than 3 months was 0.54 in our study versus 0.69 for the recent meta but our study was slightly less precise $(95 \%$ CIs were $0.40-0.74$ versus $0.55-0.87$, respectively). Effect of AVT plus corticosteroid versus AVT alone was also similar, i.e. the odds ratios for recovery were 0.49 (95\% CI: 0.36 - 0.66) versus 0.48 (95\% CI: $0.29-0.79$ ). Our results are also consistent with the updated Cochrane review [17] which found a possibility of benefit of AVT plus corticosteroid versus corticosteroid which did not reach statistical significance, with the pooled point estimate of 1.41, and with the de Almeida et al. review which also found borderline evidence for a synergistic effect of steroids and AVT[14].

We have applied a mixed model for network metaanalysis[19,31]. The mixed model gains power by integrating both direct and indirect comparisons[15]. For instance, only two studies performed direct comparisons of Acyclovir plus Prednisolone versus Prednisolone alone, a total sample size of 409 (Table 2). The network method "borrowed" information on the Prednisolone group from three other studies and increased the total sample size to 773. Although our pooled estimates were quite heterogeneous, the mixed model with random intercept takes into account variation at the study level. In addition, goodness of fit assessment suggested that our model fit well with the data. Overall, our results are quite robust since discrepancies between the direct and the network analyses are small.
Quality of included studies varied; quality assessment scores ranged from 2-12. Meta-regression of direct meta-analysis indicated that this might be a source of heterogeneity in pooling effects of AVT. However, we could not adjust for the effects of quality assessment score and other co-variables in the mixed effect model since this requires individual patient data. An individual patient data meta-analysis could be attempted, although individual level raw data are often difficult and more time consuming to access. However, with this method, covariables in both study (e.g., quality assessment) and individual levels (e.g., age, disease severity) can be assessed using a multi-level analysis approach.

\section{Conclusion}

Our evidence suggests that the current practice of treating Bell's palsy with AVT plus corticosteroid may lead to slightly higher recovery rates at 3 and 6 months compared to treating with corticosteroid alone, although at this point the sum of the data do not show that this is a significant difference; prednisone remains the best evidence-based treatment. Treating with AVT alone is significantly worse than treating with corticosteroid alone and is no better than placebo.

\section{Compteting interests}

The authors declare that they have no completing interests

\section{Additional material}

Additional file 1: Appendix

\section{List of abbreviations}

AVT: Antiviral treatment; OR: Odds ratio; Cl: Confidence interval; HSV: Herpes Simplex virus; NNT/NNH: Number needed to treat/harm

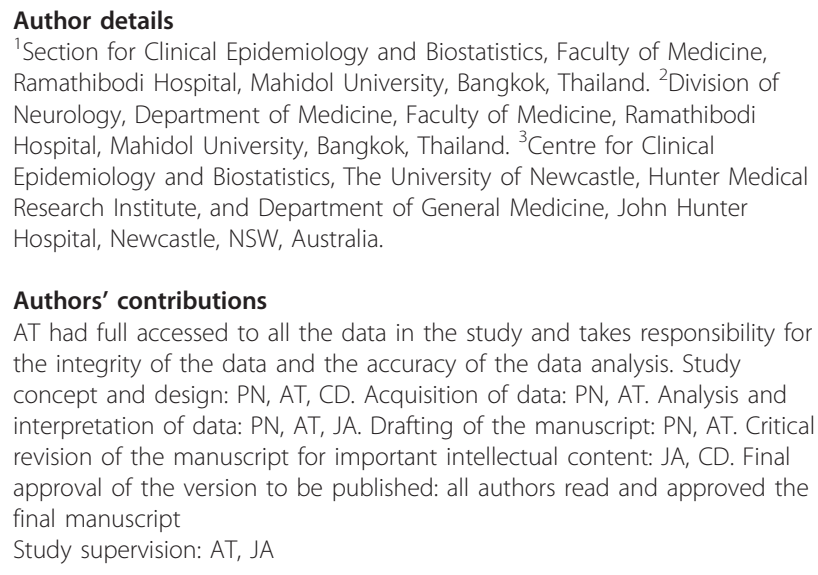
Ramathibodi Hospital, Mahidol University, Bangkok, Thailand. ²Division of Neurology, Department of Medicine, Faculty of Medicine, Ramathibodi Hospital, Mahidol University, Bangkok, Thailand. ${ }^{3}$ Centre for Clinical Epidemiology and Biostatistics, The University of Newcastle, Hunter Medical Research Institute, and Department of General Medicine, John Hunter Hospital, Newcastle, NSW, Australia.

\section{Authors' contributions}

AT had full accessed to all the data in the study and takes responsibility for the integrity of the data and the accuracy of the data analysis. Study concept and design: PN, AT, CD. Acquisition of data: PN, AT. Analysis and interpretation of data: PN, AT, JA. Drafting of the manuscript: PN, AT. Critical revision of the manuscript for important intellectual content: JA, CD. Final approval of the version to be published: all authors read and approved the final manuscript

Study supervision: AT, JA

Received: 17 February 2010 Accepted: 5 January 2011 Published: 5 January 2011 


\section{References}

1. Katusic SK, Beard CM, Wiederholt WC, Bergstralh EJ, Kurland LT: Incidence, clinical features, and prognosis in Bell's palsy, Rochester, Minnesota, 1968-1982. Ann Neurol 1986, 20:622-627.

2. Weir AM, Pentland B, Crosswaite A, Murray J, Mountain R: Bell's palsy: the effect on self-image, mood state and social activity. Clin Rehabil 1995, 9:121-125

3. Jackson CG, von Doersten PG: The facial nerve. Current trends in diagnosis, treatment, and rehabilitation. Med Clin North Am 1999, 83:179-195, x.

4. Khine H, Mayers M, Avner JR, Fox A, Herold B, Goldman DL: Association between herpes simplex virus-1 infection and idiopathic unilateral facial paralysis in children and adolescents. Pediatr Infect Dis J 2008, 27:468-469.

5. Murakami S, Mizobuchi M, Nakashiro Y, Doi T, Hato N, Yanagihara N: Bell palsy and herpes simplex virus: identification of viral DNA in endoneurial fluid and muscle. Ann Intern Med 1996, 124:27-30.

6. MacDougall C, Guglielmo BJ: Pharmacokinetics of valaciclovir. J Antimicrob Chemother 2004, 53:899-901.

7. Allen D, Dunn L: Aciclovir or valaciclovir for Bell's palsy (idiopathic facial paralysis). Cochrane Database Syst Rev 2004, CD001869.

8. Adour KK, Ruboyianes JM, Von Doersten PG, Byl FM, Trent CS, Quesenberry CP Jr, Hitchcock T: Bell's palsy treatment with acyclovir and prednisone compared with prednisone alone: a double-blind, randomized, controlled trial. Ann Otol Rhinol Laryngol 1996, 105:371-378.

9. Engstrom M, Berg T, Stjernquist-Desatnik A, Axelsson S, Pitkaranta A Hultcrantz M, Kanerva M, Hanner $P$, Jonsson L: Prednisolone and valaciclovir in Bell's palsy: a randomised, double-blind, placebocontrolled, multicentre trial. Lancet Neurol 2008, 7:993-1000.

10. Hato N, Yamada H, Kohno H, Matsumoto S, Honda N, Gyo K, Fukuda S, Furuta $Y$, Ohtani F, Aizawa $H$, et al: Valacyclovir and prednisolone treatment for Bell's palsy: a multicenter, randomized, placebo-controlled study. Otol Neurotol 2007, 28:408-413.

11. Kawaguchi $K$, Inamura H, Abe $Y$, Koshu H, Takashita E, Muraki $Y$, Matsuzaki $Y$, Nishimura $H$, Ishikawa $H$, Fukao A, et al: Reactivation of herpes simplex virus type 1 and varicella-zoster virus and therapeutic effects of combination therapy with prednisolone and valacyclovir in patients with Bell's palsy. Laryngoscope 2007, 117:147-156.

12. Sullivan FM, Swan IR, Donnan PT, Morrison JM, Smith BH, McKinstry B, Davenport RJ, Vale LD, Clarkson JE, Hammersley V, et al: Early treatment with prednisolone or acyclovir in Bell's palsy. N Engl J Med 2007, 357:1598-1607.

13. Yeo SG, Lee YC, Park DC, Cha Cl: Acyclovir plus steroid vs steroid alone in the treatment of Bell's palsy. Am J Otolaryngol 2008, 29:163-166.

14. de Almeida JR, Al Khabori M, Guyatt GH, Witterick IJ, Lin VY, Nedzelski JM, Chen JM: Combined corticosteroid and antiviral treatment for Bell palsy: a systematic review and meta-analysis. Jama 2009, 302:985-993.

15. Goudakos JK, Markou KD: Corticosteroids vs corticosteroids plus antiviral agents in the treatment of Bell palsy: a systematic review and metaanalysis. Arch Otolaryngol Head Neck Surg 2009, 135:558-564.

16. Quant EC, Jeste SS, Muni RH, Cape AV, Bhussar MK, Peleg AY: The benefits of steroids versus steroids plus antivirals for treatment of Bell's palsy: a meta-analysis. Bmj 2009, 339:b3354.

17. Lockhart P, Daly F, Pitkethly M, Comerford N, Sullivan F: Antiviral treatment for Bell's palsy (idiopathic facial paralysis). Cochrane Database Syst Rev 2009, CD001869.

18. Higgins JP, Whitehead A: Borrowing strength from external trials in a meta-analysis. Stat Med 1996, 15:2733-2749.

19. Caldwell DM, Ades AE, Higgins JP: Simultaneous comparison of multiple treatments: combining direct and indirect evidence. Bmj 2005, 331:897-900

20. Song F, Harvey I, Lilford R: Adjusted indirect comparison may be less biased than direct comparison for evaluating new pharmaceutical interventions. J Clin Epidemiol 2008, 61:455-463.

21. Vandermeer BW, Buscemi N, Liang Y, Witmans M: Comparison of metaanalytic results of indirect, direct, and combined comparisons of drugs for chronic insomnia in adults: a case study. Med Care 2007, 45:S166-172.

22. Stettler C, Wandel S, Allemann S, Kastrati A, Morice MC, Schomig A, Pfisterer ME, Stone GW, Leon MB, de Lezo JS, et al: Outcomes associated with drug-eluting and bare-metal stents: a collaborative network metaanalysis. Lancet 2007, 370:937-948.
23. Chou R, Fu R, Huffman LH, Korthuis PT: Initial highly-active antiretroviral therapy with a protease inhibitor versus a non-nucleoside reverse transcriptase inhibitor: discrepancies between direct and indirect metaanalyses. Lancet 2006, 368:1503-1515.

24. Egger M, Smith GD, Altman DG: Systematic reviews in health care: Metaanalysis in context. 2 edition. London: BMJ Books; 2001

25. De Diego JI, Prim MP, De Sarria MJ, Madero R, Gavilan J: Idiopathic facial paralysis: a randomized, prospective, and controlled study using singledose prednisone versus acyclovir three times daily. Laryngoscope 1998, 108:573-575.

26. Moreno SG, Sutton AJ, Turner EH, Abrams KR, Cooper NJ, Palmer TM, Ades AE: Novel methods to deal with publication biases: secondary analysis of antidepressant trials in the FDA trial registry database and related journal publications. Bmj 2009, 339:b2981.

27. Nuesch E, Trelle S, Reichenbach S, Rutjes AW, Tschannen B, Altman DG, Egger $M$, Juni P: Small study effects in meta-analyses of osteoarthritis trials: meta-epidemiological study. Bmj 341:c3515

28. Palmer TM, Peter $J$, Sutton AJ, Moreno SG: Contour-enhanced funnel plots in meta-analysis. The STATA journal 2008, 8:242-254.

29. Peters JL, Sutton AJ, Jones DR, Abrams KR, Rushton L: Contour-enhanced meta-analysis funnel plots help distinguish publication bias from other causes of asymmetry. J Clin Epidemiol 2008, 61:991-996.

30. Duval S, Tweedie R: Trim and fill: A simple funnel-plot-based method of testing and adjusting for publication bias in meta-analysis. Biometrics 2000, 56:455-463.

31. Lu G, Ades AE: Combination of direct and indirect evidence in mixed treatment comparisons. Stat Med 2004, 23:3105-3124.

32. Song F, Altman DG, Glenny AM, Deeks JJ: Validity of indirect comparison for estimating efficacy of competing interventions: empirical evidence from published meta-analyses. Bmj 2003, 326:472

33. Zhang J, Yu KF: What's the relative risk? A method of correcting the odds ratio in cohort studies of common outcomes. Jama 1998, 280:1690-1691.

34. Salinas RA, Alvarez G, Ferreira J: WITHDRAWN: Corticosteroids for Bell's palsy (idiopathic facial paralysis). Cochrane Database Syst Rev 2009 CD001942.

\section{Pre-publication history}

The pre-publication history for this paper can be accessed here: http://www.biomedcentral.com/1471-2377/11/1/prepub

doi:10.1186/1471-2377-11-1

Cite this article as: Numthavaj et al.: Corticosteroid and antiviral therapy for Bell's palsy: A network meta-analysis. BMC Neurology 2011 11:1.

\section{Submit your next manuscript to BioMed Central and take full advantage of:}

- Convenient online submission

- Thorough peer review

- No space constraints or color figure charges

- Immediate publication on acceptance

- Inclusion in PubMed, CAS, Scopus and Google Scholar

- Research which is freely available for redistribution 